\title{
Have You Heard of Acrometastasis?
}

\section{Daniel WJ Tan ${ }^{1}$, Fatimah Lateef ${ }^{2 *}$}

${ }^{1}$ Resident, Department of Emergency Medicine, Singapore General Hospital

${ }^{2}$ Professor and Senior Consultant, Department of Emergency Medicine, Singapore General Hospital

*Corresponding author: Fatimah Lateef, Professor and Senior Consultant, Department of Emergency Medicine, Singapore General Hospital

Received date: 13 May 2020; Accepted date: 30 May 2020; Published date: 03 June 2020

Citation: Daniel WJ Tan, Lateef F (2020) Have You Heard of Acrometastasis? J Med Case Rep Case Series 1(1):

https://doi.org/10.38207/jmcrcs20206

Copyright: (C) 2020 Fatimah Lateef. This is an open-access article distributed under the terms of the Creative Commons Attribution License, which permits unrestricted use, distribution, and reproduction in any medium, provided the original author and source are credited.

\begin{abstract}
Acrometastasis is defined as metastasis distal to the elbow and knee. It could be a rare manifestation of a widespreadmetastatic malignancy, or the first presentation in an occult malignancy. As it makes up only about $0.1 \%$ of bone metastasis, it is not commonly seen or diagnosed. However, it is important to have the awareness and high index of suspicion, in case it comes our way in our clinical practice, as we sieve through the range of differential diagnoses potentially possible in such relatively similar presentations: gout, osteomyelitis, pyogenic granuloma severe dactylitis and fingertip trauma. In this paper, we describe an anonymized case and how it poses a challenging diagnostic dilemma. We share our approach and timely management of the case.
\end{abstract}

Keywords: acrometastasis, malignancy, renal cell carcinoma

\section{Introduction}

Acrometastasis is a rare condition. It occurs in between $0.07-0.2 \%$ of all metastases and about $0.1 \%$ of bony metastasis [1]. Due to its rarity, it is often misdiagnosed as an infection or other benign condition. Here, we share a case of bilateral acrometastasis in a patient with

\section{Case Presentation}

An elderly patient presented with swelling and pain over the distal phalanges of right middle finger and leftring finger for a period of 5 months and 3 months, respectively. The pain, redness and swelling werelocalized to the distal phalanges of both right middle and left ring fingers. The pain was aggravated on palpation and moving the distal interphalangeal joints of the affected fingers. There was no associated traumaor fever. In figure $1 \mathrm{~A}$ and figure $1 \mathrm{~B}$ : AP and lateral views known metastatic renal cell carcinoma. This case highlights the need to include acrometastasis in the differential diagnosis in patients who present with swelling and such similar looking lesions of distal to the knees and elbows.

of the right middle finger and left ring finger are shown. The toes on the feet were not affected by similar looking lesions. The patient had a history of treated pulmonary tuberculosis many years ago, diabetes mellitus, hypertension and renal cell carcinoma for which a leftradical nephrectomy had been done in 1998. At that time, there were metastases to the lungs, T5 vertebra and brain.
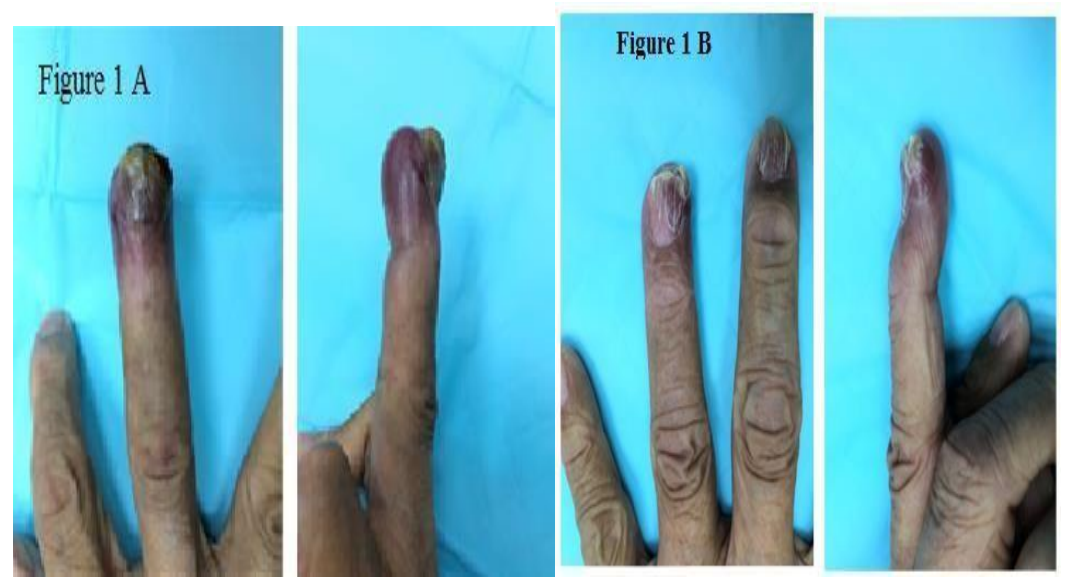

Figure $1 \mathrm{~A}$ and 1 B: AP and lateral views of the right middle finger and left ring finger

According to the patient, the pain was progressively getting worse and unbearable, that it affected the sleep. The swelling too did not resolve despite multiple visitsto the general practitioner, whereby the patient was treated for infection, with multiple courses of analgesia, oral antibiotic and topical anti-fungalcream.

The patient was admitted and underwent a right middle finger terminalisation and an incision biopsy of the left ring finger lesion. Histopathological study from the terminalised fingertip reported 
infiltrating malignant tumor involving the dermis, subcutaneous tissue and bone. It was noted that the tumour cells werein organoid, alveolated nests, interspersed by vascularized stroma. There was a focal skinulcerationover the palmar aspect of the terminal phalanx of

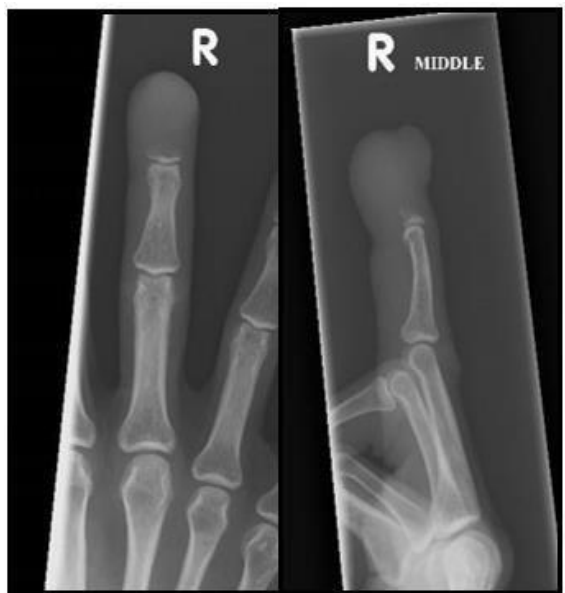

Figure 2: X-rays revealed lytic lesion on the distal phalanges of right middle and left ring fingers

\section{Discussion}

Bony metastasis is a common manifestation in many disseminated malignancies [1]. However, metastases to the hands or feet are rare occurrences, only accounting for $0.1 \%$ of all bone metastases [2]. The presence of acrometastasis is an indicator of poorprognosis as it is usually found in patients with widespread malignancy, with shortened mean life expectancy and grave prognosis [3]. Acrometastasis is usually diagnosed in patients who have known cancerbut there are some reports of it being the initial presentation of an occult malignancy [4]. Lung cancer has been reported as the most common primary malignancy associated with acrometastasis, followed by renal cell carcinoma, colorectal cancer and breast cancer $[\mathbf{5 , 6 ]}$.

These patients usually present with pain, soft tissue swelling, erythema and loss of function [7]. The pain is usually described as deep, and refractory to analgesia. Sometimes, ulceration and bleeding may develop. These signs and symptoms mimic an inflammatory process which may include several differential diagnoses such as osteomyelitis, gout, rheumatoid arthritis, tuberculous dactylitis, pyogenic granuloma and tenosynovitis [8].

It is known that bony metastasis usually involves bones rich in red marrow, such as the vertebrae. Smallbones of the extremities such as the phalanges lack red marrow. This may be the reason why acrometastasis isso rare [3]. The exact pathophysiology of metastasis tohands or feet is unknown, but there have been severalpostulations. According to the latest literature review by Stomeo et al, the tumour cells spread to the extremities via blood circulation and not lymphatic spread. This could explain the reason why the majority of

\section{Conclusion}

Acrometastases are rare and is usually linked to poor prognosis due to disseminated disease. As demonstrated in this case, an acrometastasis may mimic a benign disease such as an infection or inflammatory lesion. However, as the survival rate of cancer patients increases with the advancement of cancer therapy, we may see an

\section{Reference}

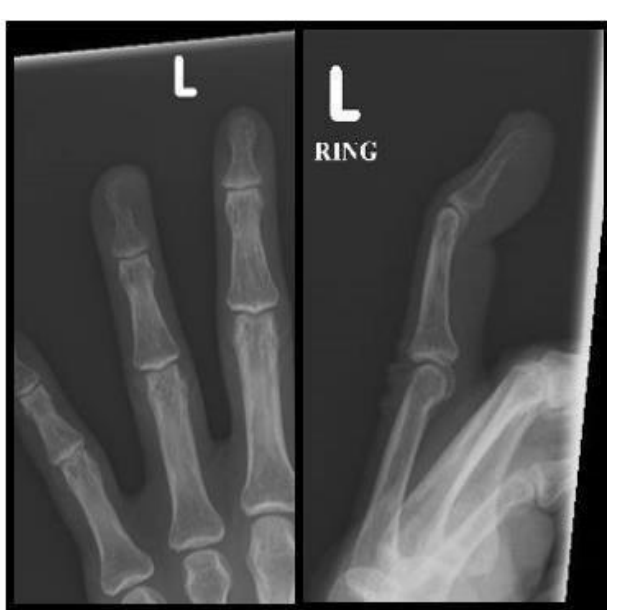

the right middle finger. The resection margins were clear of tumour cells. The features were consistent with metastasis from the primary renal cell carcinoma.

acrometastases are from primary lung cancers as they have direct access to the systemic arterial circulation, whereas tumour emboli from visceral malignancies such as renal cell carcinoma, breast cancers and colorectal cancers have to pass through the capillary beds of the pulmonary and hepatic systemfirst, making them even more rare [3]. Healey et al have suggested that acrometastasis occur more frequently in dominant hands because they receive more blood supply compared to the non-dominanthands [9]. There was also an older hypothesis by Joll et al in 1923 that suggested trauma induced acrometastasis. He described that repeated injury may reduce the surrounding tissue's resistance, allowing tumour emboli to seed and grow in the bones [10]. This theory is supported by another author who suggested that the release of chemotactic factors, such as prostaglandin, after trauma, may promote the migration and adherence of cancer cells to the bones [11].

There are no standard protocols pertaining to the treatment of acrometastasis, especially as these cases are so rare $[2,3]$. Due to their poor prognosis, most of the cases are usually evaluated on a case by case basis with treatment mainly aimed at palliation, adequate resection of tumour, relief of pain, for quick recovery and preservation of maximal hand function $[\mathbf{2 , 1 2}]$. Amputation is the most common treatment option, especially for acrometastasis to the distal phalanges. Radiotherapy has also been shown to be able to achieve pain relief and gain local control of the disease. This is useful for acrometastasis involving areas such as metacarpals where amputation is not an option [6]

increase in these casesin the future. Hence, physicians should have highindex of suspicion for possible metastatic malignant lesion in patients presenting with painful swollen digit. A timely diagnosis and treatment of this condition may potentially improve patient's quality of life. 
1. Hernandez-Cortes P, Caba-Molina M, Gomez-Sanchez R, RiosPeregrina R (2015)Renal Clear Cell Carcinoma Acrometastasis. An Unusual Terminal Condition. J Hand Microsurg 7(1): 149151 .

2. Mavrogenis AF, Mimidis G, Kokkalis ZT, Karampi ES, Karampela I, et al. (2014) Acrometastases. Eur J Orthop Surg Traumatol 24(3): 279-283.

3. Stomeo D, Tulli A, Ziranu A, Perisano C,DeSantis V, et al. (2015) Acrometastasis: a literature review. Eur Rev Med Pharmacol Sci 19(15): 2906-2915.

4. Abrahams TG (1995) Occult Malignancy Presenting as Metastatic Disease to the Handand Wrist. Skeletal Radiol 24(2): 135-137.

5. Kerin R (1983) Metastatic tumors of the hand. A review of the literature. J Bone JointSurg Am 65(9): 1331-1335.

6. Flynn CJ, Danjoux C, Wong J, Christakis M, Rubenstein J, et al. (2008) Two cases of acrometastasis to the hands and review ofthe literature. Curr Oncol 15(5): 51-58.

7. Khokhar N, Lee JD (1983) Phalangeal metastasis: first clinical sign ofbronchogeniccarcinoma. South Med J 76(7): 927.

8. Bevan DA, Ehrlich GE, Gupta VP (1977) Metastatic carcinoma simulating gout. JAMA 237(25): 2746-2747.

9. Healey JH, Turnbull AD, Miedema B, Lane JM (1986) Acrometastases. A study of twenty-nine patients with osseous involvement of the hands and feet. J Bone Joint Surg Am 68(5): 743-746.

10. Joll CA (1923) Metastatic tumors of bone. BrJ Surg 11: 38-72.

11. Tolo ET, Cooney WP, Wenger DE (2002) Renal cell carcinoma with metastases to the triquetrum: case report. J Hand Surg [Am] 27(5): 876-881.

12. Spiteri V, Bibra A, Ashwood N, Cobb J (2008) Managing acrometastases treatment strategy with a case illustration. Ann R Coll Surg Engl 90: 8-11. 